\title{
Variation in root secondary metabolites is shaped by past climatic
} conditions

3 Münster, Germany

9

10 Correspondence: Matthias Erb (matthias.erb@ips.unibe.ch), University of Bern, Institute of

11 Plant Sciences, Altenbergrain 21, 3013 Bern, Switzerland 


\section{Abstract}

1. Plants can adapt to changing environments by adjusting the production and maintenance of diverse sets of bioactive secondary metabolites. To date, the impact of past climatic conditions relative to other factors such as soil abiotic factors and herbivore pressure on the evolution of plant secondary metabolites is poorly understood, especially for plant roots.

2. We explored associations between root latex secondary metabolites in 63 Taraxacum officinale populations across Switzerland and past climatic conditions, soil abiotic parameters, and root herbivore pressure. To assess the contribution of environmental effects, root secondary metabolites were measured in F0 plants in nature and F2 plants under controlled greenhouse conditions.

3. Concentrations of root latex secondary metabolites were most strongly associated with past climatic conditions, while current soil abiotic factors or root herbivore pressure did not show a clear association with root latex chemistry. Results were identical for natural and controlled conditions, suggesting heritable trait variation rather than environmental plasticity as underlying factor.

4. Synthesis. We conclude that climatic conditions likely play a major role in the evolution of root secondary metabolites. Direct abiotic effects are likely underlying this pattern, hinting at a novel role of root latex metabolites the tolerance of abiotic stress.

Keywords: climatic conditions, dandelion, environmental gradient latex, herbivore defence, intraspecific variation, multifunctionality, secondary metabolites, 


\section{Introduction}

Plants produce a tremendous variety of structurally diverse organic compounds, socalled secondary or specialized metabolites. These metabolites defend plants against herbivores and pathogens (Mithöfer \& Boland, 2012) increase abiotic stress tolerance (de Costa, Yendo, Fleck, Gosmann, \& Fett-Neto, 2013; Hazarika \& Rajam, 2011; Qi, Yang, Yuan, Huang, \& Chen, 2015), facilitate mutualisms (Peters, Frost, \& Long, 1986; Schäfer et al., 2009; Stevenson, Nicolson, \& Wright, 2017), promote micronutrient uptake (Hu et al., 2018; Kobayashi \& Nishizawa, 2012), or act as growth and defence regulators (Francisco et al., 2016; Kim, Ciesielski, Donohoe, Chapple, \& Li, 2014; Malinovsky et al., 2017). Although secondary metabolites can have highly specialized functions, there is growing evidence that individual many of them serve multiple purposes (Hu et al., 2018; Katz et al., 2015; J. Li et al., 2018; Malinovsky et al., 2017; Møller, 2010). Multifunctional secondary metabolites help the plant to minimize the effort required for biosynthesis and compound maintenance and are therefore seen as a cost-effective resource allocation strategy (reviewed in Neilson, Goodger, Woodrow, \& Møller, 2013).

Given the importance of secondary metabolites in adjusting a plant's physiology to its continuously changing environment, abiotic and biotic factors are expected to exert strong selective pressure on plant secondary metabolism (Hartmann, 2007). Hence, metabolite profiles can vary substantially even within the same species. The unique set of secondary compounds produced by a plant population likely reflects the particular demands of the plant's ecological niche and its current selective environment (Moore, Andrew, Külheim, \& Foley, 2014). In Arabidopsis thaliana populations, for instance, geographic variation in the abundance of $A$. thaliana chemotypes is strongly associated with the geographic pattern in the relative abundance of two specialist herbivores (Züst et al., 2012). Patterns of secondary metabolite profiles across populations have also been directly or indirectly linked to geographical gradients such as latitude or elevation (Abdala-Roberts, Moreira, Rasmann, Parra-Tabla, \& Mooney, 2016; Anstett, Ahern, Johnson, \& Salminen, 2018; Coll Aráoz, Mercado, Grau, \& Catalán, 2016; Moles et al., 2011; Woods et al., 2012). As changes in geographic locations are associated with substantial variation in both biotic and abiotic traits, integrated analyses that take different environmental parameters into account are helpful to identify the environmental factors that 
shape the evolution and expression of plant secondary metabolites in natural populations.

Intraspecific variation in secondary metabolites can be constitutive (Züst et al., 2012). and can be further amplified by phenotypic plasticity (Huber, Bont, et al., 2016). To partition this natural variation into constitutive, genetically fixed and inducible, plastic components, common garden experiments provide a useful tool (Anstett et al., 2018; Hahn, Agrawal, Sussman, \& Maron, 2018; Stevens, Brown, Bothwell, \& Bryant, 2016) as they control for the contribution of the variation induced by the local environment. In a common garden study with Artemisia californica, for instance, Pratt, Keefover-Ring, Liu, and Mooney (2014) showed that geneticallybased variation in terpene composition and monoterpene concentration is associated with latitude of the source population and the corresponding differences in precipitation. Furthermore, comparing the production of secondary metabolites under controlled environmental conditions with their production in the plant's natural habitat allows the assessment of environmental plasticity (Abdala-Roberts et al., 2016; Castillo et al., 2013). Thus, studies that measure secondary metabolites among populations in both their natural habitat and in common gardens can help determine to what extent a plant's chemical phenotype is fixed or plastic in response to its environment (Hahn et al., 2018).

Many secondary metabolites are found in both roots and shoots of a plant, yet as a result of the distinct functions of these two plant parts (van Dam, 2009) composition and regulation of metabolites often differ above and below ground (Hartmann, 2007; Johnson, Erb, \& Hartley, 2016). Changes in abiotic factors result in different morphological and physiological responses in roots compared to shoots, with different metabolic patterns that seem to allow complementary adjustments above and below ground through phenotypic plasticity (GargalloGarriga et al., 2015; Mithöfer \& Boland, 2012; Rasmann \& Agrawal, 2008). Above ground, climatic conditions of natural habitats have been shown to shape heritable intraspecific variation of secondary metabolites (Hahn et al., 2018; Pratt et al., 2014), indicating that past and present climatic characteristics select for specific chemotypes. Below ground, climatic conditions likely influence heritable variation of secondary metabolites as well, but experimental evidence for such effects is lacking so far. Furthermore, soil physical and chemical properties such as humus content or $\mathrm{pH}$ may affect plant physiology by determining the amount and composition of available nutrients (Dubuis et al., 2013), which in turn can result in differences in plant chemistry 
95 (Cunningham, Summerhayes, \& Westoby, 1999; Meindl, Bain, \& Ashman, 2013). In addition to

96 abiotic factors, biotic factors such as herbivores have been identified to drive intraspecific

97 variation of defensive secondary metabolites in the leaves (Agrawal, 2011; Schuman \&

98 Baldwin, 2016; Züst et al., 2012) and recently also in the roots (Huber, Bont, et al., 2016).

99 Although the effects of specific environmental factors on plant secondary metabolites have

100 been studied extensively, the simultaneous and combined effects of abiotic and biotic factors

101 including climatic conditions, soil geochemical properties and herbivores on heritable variation

102 in plant secondary metabolites remain poorly understood, especially below ground.

103 In this study, we investigated the role of abiotic and biotic factors in shaping variation

104 in root secondary metabolites of the globally distributed common dandelion, Taraxacum

105 officinale agg. (Asteraceae), as a model system. Dandelion accumulates toxic secondary

106 metabolites primarily in latex, a milky, often sticky sap that is transported and stored in

107 pressurized laticifers, to be released upon damage by herbivores. Laticifers allow for

108 compartmentalised storage and deployment of toxic compounds while also preventing

109 autotoxicity by the often highly reactive substances (Hagel, Yeung, \& Facchini, 2008). Latex

110 can be found in approximately $10 \%$ of all flowering plant species and contains a rich variety of

111 secondary metabolites (Agrawal \& Konno, 2009; Castelblanque et al., 2017). Based on its

112 physical and chemical properties, latex has been associated with defensive functions against

113 herbivores and pathogens, and no other functions are currently known (Konno, 2011).

114 Our previous work revealed that latex of $T$. officinale contains three major classes of 115 secondary metabolites: the sesquiterpene lactone taraxinic acid ß-D-glucopyranosyl ester (TA116 G), hydroxyphenylacetate inositol esters with either two or three side chains (di-PIEs 117 respectively tri-PIEs) and several triterpene acetates (TritAc) (Huber et al., 2015). Both TA-G 118 and PIEs are involved in defence against herbivores and are highly variable among natural 119 populations (Agrawal, Hastings, Fines, Bogdanowicz, \& Huber, 2018; Bont et al., 2017; Huber, 120 Bont, et al., 2016; Huber, Epping, et al., 2016), and we have demonstrated that the 121 concentration of TA-G is shaped by selection from the major native root herbivore Melolontha 122 melolontha (Huber, Bont, et al., 2016). However, both abiotic and biotic environmental factors 123 can influence the quantity of latex exudation (Barton, 2014; Raj, Das, Pothen, \& Dey, 2005; 124 Woods et al., 2012) and the relative composition of the diverse latex secondary metabolite 
125 mixtures may be likewise affected by environmental conditions, although experimental

126 evidence for this assumption is scarce.

127 Here, we investigated environmental drivers of intraspecific variation in root latex

128 secondary metabolites of $T$. officinale. Focusing on the main secondary metabolites of $T$.

129 officinale latex, we determined metabolite profiles of 63 populations growing in their natural

130 habitat and of their offspring grown under controlled conditions in the greenhouse. We recorded

131 and inferred current and historic root herbivore abundance as well as soil geochemical

132 parameters in the natural habitats of the different populations. We furthermore retrieved climatic

133 conditions of the different habitats over the last 20 years, and performed model selection to

134 determine which environmental variables are most strongly associated with naturally expressed

135 and heritable variation in root secondary metabolites. 


\section{Materials and methods}

137 Study species

138 The common dandelion, $T$. officinale, is a latex-producing perennial herb native to

139 Eurasia (Stewart-Wade, Neumann, Collins, \& Boland, 2002). It is described as a species

140 complex that consists of diploid outcrossing, triploid apomictic and, in rare cases, tetraploid

141 individuals (Verduijn, Van Dijk, \& Van Damme, 2004). In Switzerland, T. officinale most

142 commonly colonizes low- and mid-elevation habitats, but can also be found at altitudes higher

143 than $2000 \mathrm{~m}$ a.s.I. (Calame \& Felber, 2000). The main peak flowering time of $T$. officinale in the

144 northern hemisphere is from April to June, with plants growing in warmer habitats at lower

145 altitude flowering earlier than plants growing in colder habitats. Approximately 10-12 days after

146 flowering, seed maturation is completed and each capitulum produces several hundred seeds

147 equipped with a parachute-like structure to facilitate wind dispersal (Honek \& Martinkova,

148 2005). Using a simulation model for wind dispersal, Tackenberg, Poschlod, and Kahmen,

149 (2003) calculated that more than $99.5 \%$ of released dandelion seeds land within $10 \mathrm{~m}$ distance,

150 whereas $0.014 \%$ had the potential to be dispersed $>1 \mathrm{~km}$. Pollination, on the other hand, occurs

151 mainly within a range of a few meters (Lázaro \& Totland, 2010; Takakura, Matsumoto, Nishida,

152 \& Nishida, 2011). Thus, although occasional long-distance seed dispersal events occur, gene

153 flow between distant populations is likely restricted due to limitations in dispersal distances of

154 pollen and seeds.

155 Field sites and environmental data

156 From April to June 2016, we identified and characterized $63 \mathrm{~T}$. officinale populations

157 across Switzerland in situ. Populations were selected based on proximity to meteorological

158 monitoring stations of MeteoSwiss, the Swiss Federal Office for Meteorology and Climatology,

159 with all field sites being located within a maximal distance of $1 \mathrm{~km}$ from a station. Based on this

160 criterion we evenly distributed the sampling sites across Switzerland, with altitudes of

161 populations ranging from 200 - 1600 m a.s.I., (Fig. 1, Table S1). Each population was visited

162 once towards the end of its flowering period. On each field site, we marked a square of $25 \mathrm{~m}^{2}$

163 in a representative area of the field and haphazardly selected $15 T$. officinale plants within this

164 square for latex and seed collection. Where available, information on land use intensity over 165 the last decades was obtained from landowners. To characterize long-term climatic conditions, 
bioRxiv preprint doi: https://doi org/10.1101/2020.01 25.919654: this version posted January 25, 2020. The copyright holder for this preprint (which was not certified by peer review) is the author/funder, who has granted bioRxiv a license to display the preprint in perpetuity. It is made available under aCC-BY-NC-ND 4.0 International license.

ten variables were selected from the MeteoSwiss database (Table 1). The chosen variables

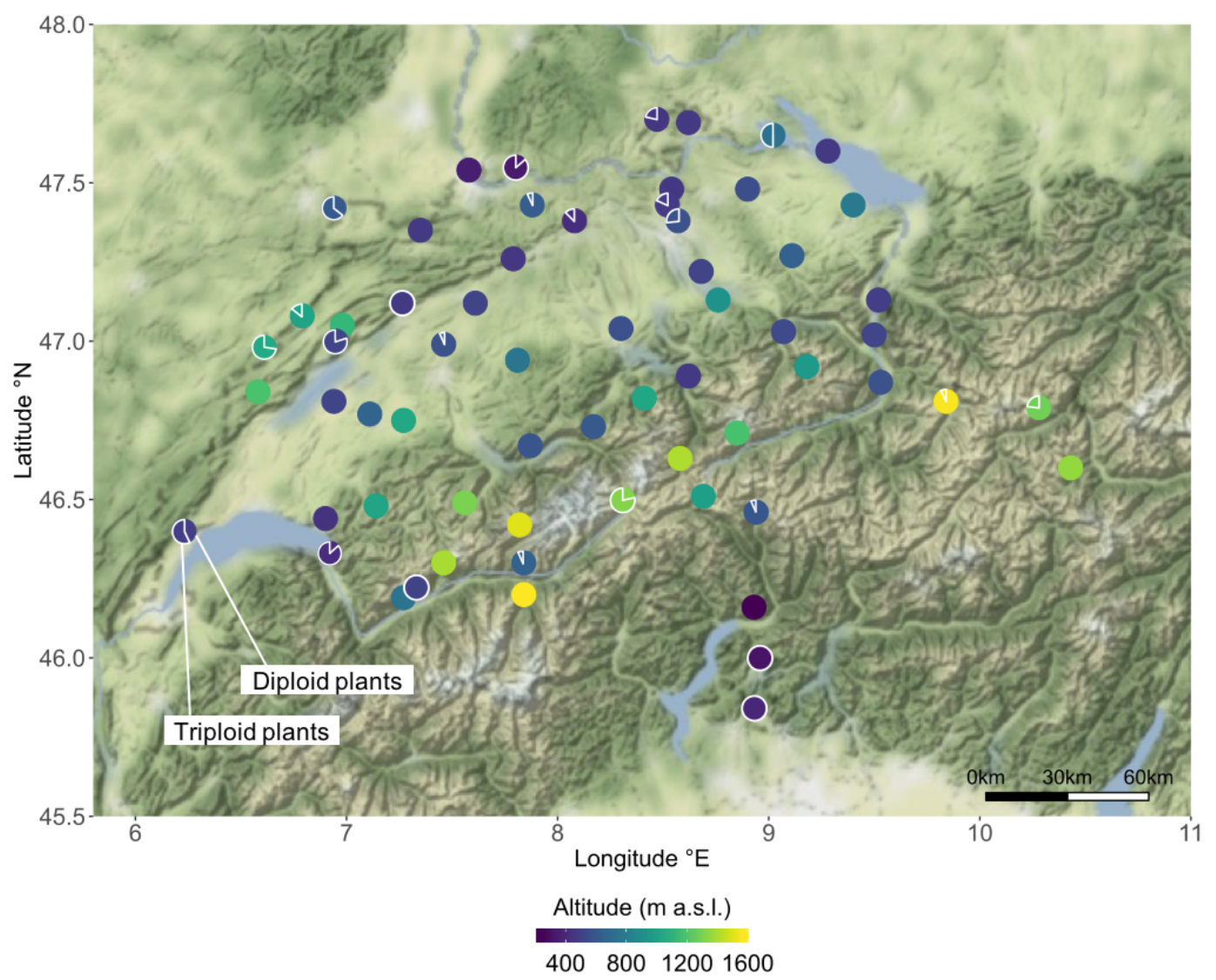

Figure $1 \mathrm{~T}$. officinale sampling locations across Switzerland. Each circle displays one of the 63 sampled populations. Colour gradient of the circle fill represents the altitude of the populations. The proportion of the circle that is outlined in white colour corresponds to the percentage of triploid plants of the respective population, whereas the unmarked part of the circle corresponds to the percentage of diploids.

For soil analysis, soil samples were taken from each field site. We used a 'Swiss

179 Sampler' (Eric Schweizer AG, Thun, Switzerland) to take 15 soil samples of the top $15-20 \mathrm{~cm}$

180 soil layer along one diagonal of the $25 \mathrm{~m}^{2}$ square. Soil samples were then pooled and stored 181 at $4{ }^{\circ} \mathrm{C}$ after returning to the lab. Each pooled sample was then analysed for PEP (proof of 182 ecological performance) (performed by Labor für Boden- und Umweltanalytik, Eric Schweizer 183 AG, Thun, Switzerland). From this data we selected humus content and soil pH for further 
184 analyses because both are important determinants of the amount and composition of available

185 nutrients for plants and thus influence plant physiology (Dubuis et al., 2013).

186 To assess the abundance of belowground herbivores we used two approaches: first,

187 three of the 15 selected dandelion plants were excavated in the field, and the number of

188 belowground herbivores in the rhizosphere and surrounding soil core (approximately $15 \times 15 \times$

$18915 \mathrm{~cm}$ ) was counted and averaged per plant. Second, we categorized the field sites belonging

190 to either an area with historically high density of Melolontha melolontha or an area with no or

191 only low density of M. melolontha over the last decades (Huber, Bont, et al., 2016). The larvae

192 of M. melolontha are one of the major native root herbivores of $T$. officinale and can severely

193 impair the plant (Hauss \& Schütte, 1976; Huber, Bont, et al., 2016). Due to the low mobility of

194 larvae and habitat fidelity of adults, local populations of $M$. melolontha remain stable over long

195 periods of time, and in a previous study we found that past M. melolontha abundance is a good

196 predictor of present M. melolontha pressure (Huber, Bont, et al., 2016).

197 Generation of F2 plants

198 To investigate heritable variation in latex secondary metabolites, we grew plants from

199 field-collected seeds in a greenhouse for two generations. F2 plants were obtained by

200 controlled hand-pollination between F1 plants of the same population. Initially, we collected one

201 seed head from each of the 15 selected F0 mother plants per field site during the field visits. In

202 August $2016, \mathrm{~F} 1$ seeds were germinated in a greenhouse $\left(22^{\circ} \mathrm{C}\right.$ day / $18{ }^{\circ} \mathrm{C}$ night; $16 \mathrm{~h}$ light /

$2038 \mathrm{~h}$ darkness) by sowing $10-15$ seeds per collected seed head into a small pot ( $5.5 \mathrm{~cm}$ diameter)

204 filled with moist seedling substrate. After three weeks, three seedlings of each mother plant

205 were transplanted together as a seed family into one bigger pot $(13 \times 13 \times 13 \mathrm{~cm})$ filled with

206 potting soil (5 parts field soil, 4 parts peat, and 1 part sand). As not all seeds germinated, we

207 obtained between 6 and 15 seed families per population, with a total of 931 pots. One week

208 after transplantation, pots were put outside for growth and natural vernalisation during fall of

209 2016. In November 2016, pots were transported into a semi-controlled greenhouse

210 (temperature between 15 and $25^{\circ} \mathrm{C}, 16 \mathrm{~h}$ light and $8 \mathrm{~h}$ darkness), where flower production

211 started after 1-2 months. Across all populations at least one plant per population produced

212 flowers, however, number of flowering plants varied between populations. To avoid cross-

213 pollination between populations, flower buds were covered with a tea bag before flower 
214 opening. Whenever flowers of two plants from different seed families within the same 215 population were open concurrently, tea bags of those flowers were removed, flowers were 216 carefully rubbed against each other for pollination and then covered again with tea bags until 217 seed collection. As triploid plants reproduce clonally, pollination is only necessary for the 218 obligate outcrossing diploids. However, at the time of pollination, ploidy level of F1 plants was 219 unknown, thus, hand-pollination was done for all plants. After collection, seeds were stored at $2204^{\circ} \mathrm{C}$.

221 To grow F2 plants for latex analysis, we included all populations for which we could 222 collect seeds from 3-6 different F1 plants per population. We excluded eight of the 63 223 populations for having fewer than three seed-producing F1 plants. Ploidy level analysis of F1 224 plants (see below) revealed that populations with mixtures of diploid and triploid cytotypes were 225 frequent (Fig. 1). F1 parent plants were selected according to their ploidy level to represent the 226 ratio of diploid and triploid plants of each population. Rarely occurring tetraploid plants were 227 excluded. For populations with more than $75 \%$ diploid plants, all parent plants for the $\mathrm{F} 2$ seeds 228 were chosen to be diploid. For populations with $50-75 \%$ diploid plants, $2 / 3$ diploid and $1 / 3$ 229 triploid plants were chosen as parent plants. For populations with $25-50 \%$ diploid plants, $1 / 3$ 230 diploid and $2 / 3$ triploid plants were chosen as parent plants. For population with less than $25 \%$ 231 diploid plants, all parent plants were chosen to be triploid. Seeds were germinated in a 232 greenhouse $\left(22^{\circ} \mathrm{C}\right.$ day / $18^{\circ} \mathrm{C}$ night; $16 \mathrm{~h}$ light / $8 \mathrm{~h}$ darkness) on moist seedling substrate. 233 After three weeks, one seedling per parent was transplanted into a pot $(9 \mathrm{~cm} \times 9 \mathrm{~cm} \times 9 \mathrm{~cm})$ 234 filled with garden soil (Selmaterra, Eric Schweizer AG, Thun, Switzerland), resulting in a total 235 of 256 pots. Pots were kept in the greenhouse in a randomized fashion until latex collection.

236 Ploidy level

237 To estimate the percentage of diploid, triploid and tetraploid plants per population, DNA 238 ploidy level of F1 plants was determined by flow cytometry. A CyFlow Cube (Sysmex Partec $239 \mathrm{GmbH}$, Goerlitz, Germany) with a Partec CyStain UV precise P kit (ref. 05-5002) was used 240 following the manufacturer's instructions. Ploidy level was determined using fresh tissue from 241 one leaf per plant per pot. As external standard, leaf tissue of $T$. officinale plants with known 242 ploidy level (diploid or triploid) was used. Ploidy levels of F1 plants were estimated by 
243 comparing the sample peak to the standard peak. Approximately 1500 nuclei were measured

244 per sample.

245 Latex collection and chemical analysis

246 Latex from F0 plants was collected in each field site from the 15 plants that were

247 selected for seed collection. Latex from F2 plants was collected in the greenhouse when plants

248 where three months old. To obtain taproot latex, each plant was cut $0.5 \mathrm{~cm}$ below the tiller and

$2492 \mu \mathrm{l}$ of the exuding latex was pipetted immediately into $200 \mu \mathrm{l}$ methanol. After returning to the

$250 \mathrm{lab}$, latex samples were stored at $-20^{\circ} \mathrm{C}$ until processing. For extraction of latex secondary

251 metabolites, tubes were vortexed for $10 \mathrm{~min}$, ultrasonicated for $10 \mathrm{~min}$, centrifuged at $4{ }^{\circ} \mathrm{C}$ and

$25214000 \mathrm{rpm}$ for $20 \mathrm{~min}$ and supernatants were stored at $-20^{\circ} \mathrm{C}$. For F0 plants, pooled samples

253 per population were made for chemical analysis by mixing $10 \mu \mathrm{l}$ of methanol extract from each

254 of the 15 plants per population in an Eppendorf tube. For F2 plants, methanol extracts from

255 individual samples were used for chemical analysis and average concentrations per population

256 were calculated afterwards. Relative concentrations of TA-G, di-PIEs and tri-PIEs were

257 determined as described in Bont et al. (2017). In brief, methanol extracts were injected into an

258 Acquity UPLC-PDA-MS (Waters, Milford MA, USA) with electrospray ionization in positive

259 mode, consisting of an ultra-performance liquid chromatograph (UPLC) coupled to a

260 photodiode array detector (PDA) and a single quadrupole mass detector (QDa). For

261 quantification, peak areas were integrated at $245 \mathrm{~nm}$ for TA-G and at $275 \mathrm{~nm}$ for di- and tri-

262 PIES, while concurrently recorded characteristic mass features were used to confirm

263 compound identities.

264 Statistical analysis

265 To disentangle heritable variation in latex secondary metabolites and variation due to

266 environmental plasticity, we performed linear regression analyses within each class of

267 secondary metabolites to investigate how the chemistry of F2 plants is related to the chemistry

268 of F0 plants. If, within a class of secondary metabolites, the linear regression between F2 plants

269 and F0 plants was statistically significant, we used the slope of this regression as an

270 approximate estimate for narrow-sense heritability (pseudo- $h^{2}$ ) (Falconer, 1981). We also

271 compared patterns of covariation among latex metabolites by testing for correlations between

272 the three metabolite classes within F0 plants and within F2 plants separately. 
To investigate the effects of climate, soil and belowground herbivores on the latex

274 profile of $T$. officinale, we applied a set of linear mixed-effects models across all populations.

275 As the climate dataset showed multicollinearity, we first applied a principal component analysis

276 (PCA) on the ten selected meteorological variables to reduce dimensionality. We scaled the

277 variables and used the function 'prcomp' in R to extract the values of the first (climPCA1) and

278 the second (climPCA2) axis. Both axes together explained $76 \%$ of the variation in the original

279 climate data and were then used to represent the climatic conditions of each population. In

280 order to analyse whether the climatic conditions are linked with the geographical localisation of

281 the populations, we tested for correlations between the climatic PCA axes and altitude, latitude

282 and longitude of the populations. Further, we tested for correlations among the variables that

283 represent climatic conditions, soil geochemical properties and root herbivore abundance. For

284 linear mixed-effects model analysis, we used the function 'Imer' from the package 'Ime4' (Bates,

285 Maechler, Bolker, \& Walker, 2015) to fit models for each T. officinale generation (F0 and F2)

286 and each latex secondary metabolite class (TA-G, di-PIEs, tri-PIEs) separately. The response

287 variable was the population mean of the respective secondary metabolite class and climPCA1,

288 climPCA2, humus content, soil pH, M. melolontha area (yes / no) and number of belowground

289 herbivores per plant of each population were used as fixed factors. The categorical percentages

290 of diploid plants per population $(0-24 \%, 25-74 \%, 75-100 \%)$ were added as a random factor, as

291 sexual diploids and asexual triploids have a different reproduction system, which can affect the

292 heritability of a trait. Interaction terms were not included in the models. If necessary, response

293 variables were log-transformed to improve distribution of variance. Effect sizes were estimated

294 using restricted maximum likelihood (REML). Models were validated using 'plotresid' from the

295 package 'RVAideMemoire' (Hervé, 2018). The significances of the fixed effects were estimated

296 by Wald chi-square tests using the function 'Anova' from the package 'car' (Fox \& Weisberg,

297 2011). In order to facilitate the visualization of significant model effects, we additionally

298 performed separate linear regressions for each significant fixed factor in the Imer models.

299 Similar results were obtained with models for values of individual plants, which included

300 population as additional random factor, compared to models for mean values per population.

301 A map of all populations was created with 'ggmap' (Kahle \& Wickham, 2013), 'viridis'

302 (Garnier, 2018) and 'ggsn' (Baquero, 2017). Results were visualized using ggplot2 (Wickham, 
bioRxiv preprint doi: https://doi.org/10.1101/2020.01.25.919654; this version posted January 25, 2020. The copyright holder for this preprint (which was not certified by peer review) is the author/funder, who has granted bioRxiv a license to display the preprint in perpetuity. It is made available under aCC-BY-NC-ND 4.0 International license.

303 2016) and factoextra (Kassambara \& Mundt, 2017). All statistical analyses were performed in

304 R 3.4.0 (R Core Team, 2017). 
a

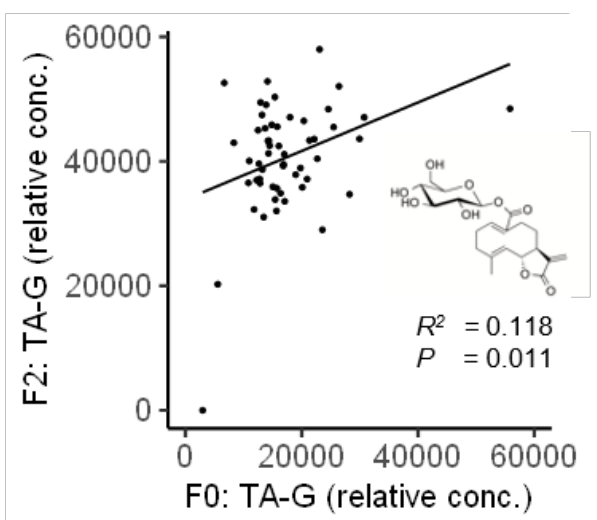

C

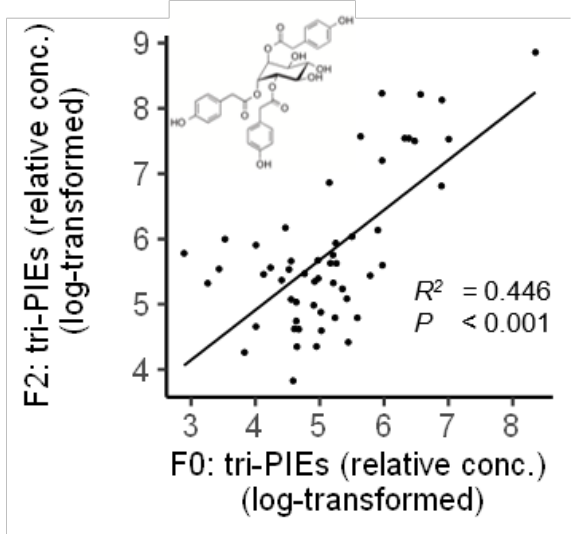

b

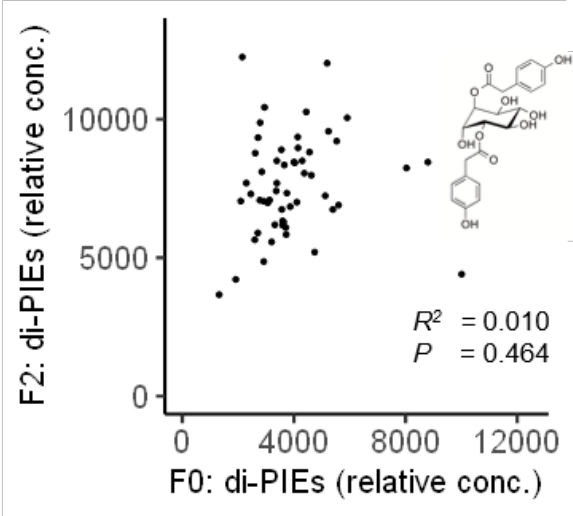

Figure 2 Relationship between the latex chemistry of the plants growing in natural habitat (F0) and the plants growing in greenhouse conditions (F2). Regression analyses were performed separately for TA-G (a), di-PIEs (b) and tri-PIEs (c). Each dot represents one of the 63 sampled $T$. officinale populations. $R^{2}$ - and $P$-values are displayed and, for statistically significant regressions $(P<0.05)$, linear regression lines are shown. TA-G: taraxinic acid ß-Dglucopyranosyl ester; di-PIEs: di-4-hydroxyphenylacetate inositol esters; tri-PIEs: tri-4hydroxyphenylacetate inositol esters.

Both in natural habitats (F0 plants) and under greenhouse conditions (F2 plants), the production of latex secondary metabolites varied greatly across $T$. officinale populations (Figs. S1-S3). In the field, TA-G differed almost 19-fold (Fig. S1a), di-PIEs more than sevenfold (Fig. S2a) and tri-PIEs more than 200-fold (Fig. S2c) among populations. Under greenhouse conditions, mean concentrations of latex secondary metabolites were increased but varied less among populations. Nonetheless, average concentrations of TA-G still differed almost threefold 
323 (Fig. S1b; average calculated without one population that produced almost no TA-G), di-PIEs

324 more than threefold (Fig. S2b) and tri-PIEs more than 150-fold (Fig. S3b) among populations.

325 The mean production of latex metabolites by F2 plants was partially predicted by mean

326 concentrations in F0 plants for TA-G $\left(R^{2}=0.12, F_{(1,52)}=6.07, P=0.01\right.$, Fig 2a $)$ and tri-PIEs $\left(R^{2}\right.$

$327=0.45, F_{(1,52)}=41.78, P<0.001$, Fig. $\left.2 \mathrm{c}\right)$. This suggests that heritable genetic variation

328 contributed to the variation in these secondary metabolites, with estimated narrow-sense

329 heritabilities (slope \pm SE) of $0.39 \pm 0.15$ for TA-G and $0.77 \pm 0.12$ for tri-PIEs. For di-PIEs, no

330 statistically significant influence of the production of plants growing in natural habitats (F0) on

331 the production of plants growing under greenhouse conditions (F2) was found (Fig. 2b).

332 Environmental plasticity contributes to variation in latex secondary metabolites

333 In order to examine covariation of latex metabolite concentrations and to assess the

334 additional component of environmental plasticity besides heritable variation in the latex profiles,

335 we tested for pairwise correlations among the three classes of secondary metabolites for plants

336 growing in natural habitat (F0) and plants growing in the greenhouse (F2). The analysis

337 revealed that for F0 plants, TA-G, di-PIEs and tri-PIEs were significantly positively correlated

338 with each other (TA-G and di-PIEs: Pearson's $r=0.76, P<0.001$; TA-G and tri-PIEs: Pearson's

$339 r=0.66, P<0.001$; di-PIEs and tri-PIEs: Pearson's $r=0.42, P<0.001$; Fig 3a). In contrast,

340 only TA-G and di-PIEs were positively correlated for F2 plants (Pearson's $r=0.38, P=0.004$,

341 Fig 3b), while TA-G and tri-PIEs were not significantly correlated (Pearson's $r=0.04, P=0.78$,

342 Fig 3b) and di-PIEs and tri-PIEs were negatively correlated (Pearson's $r=-0.41, P=0.002$, Fig

$3433 b)$. This finding indicates that the regulation of latex secondary metabolites is plastic in

344 response to the environment and not solely determined by genetic, heritable variation. 
a

Plants growing in natural habitat (F0)
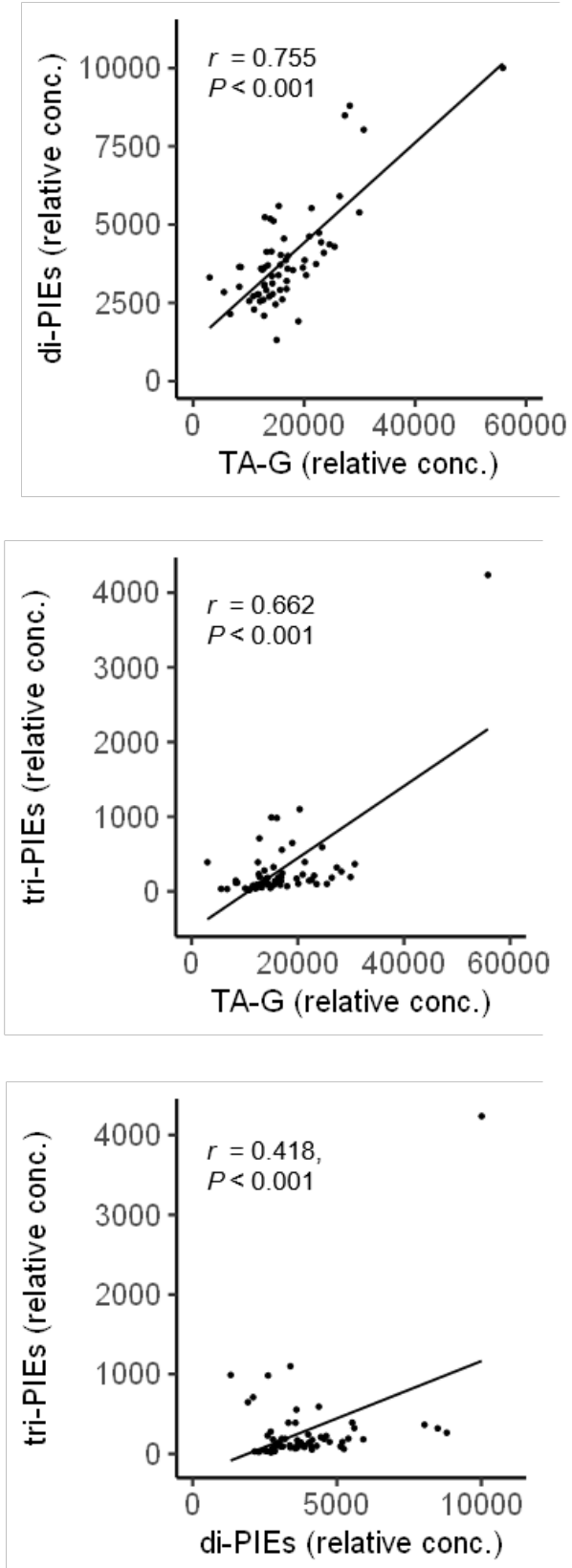

b Plants growing in greenhouse (F2)
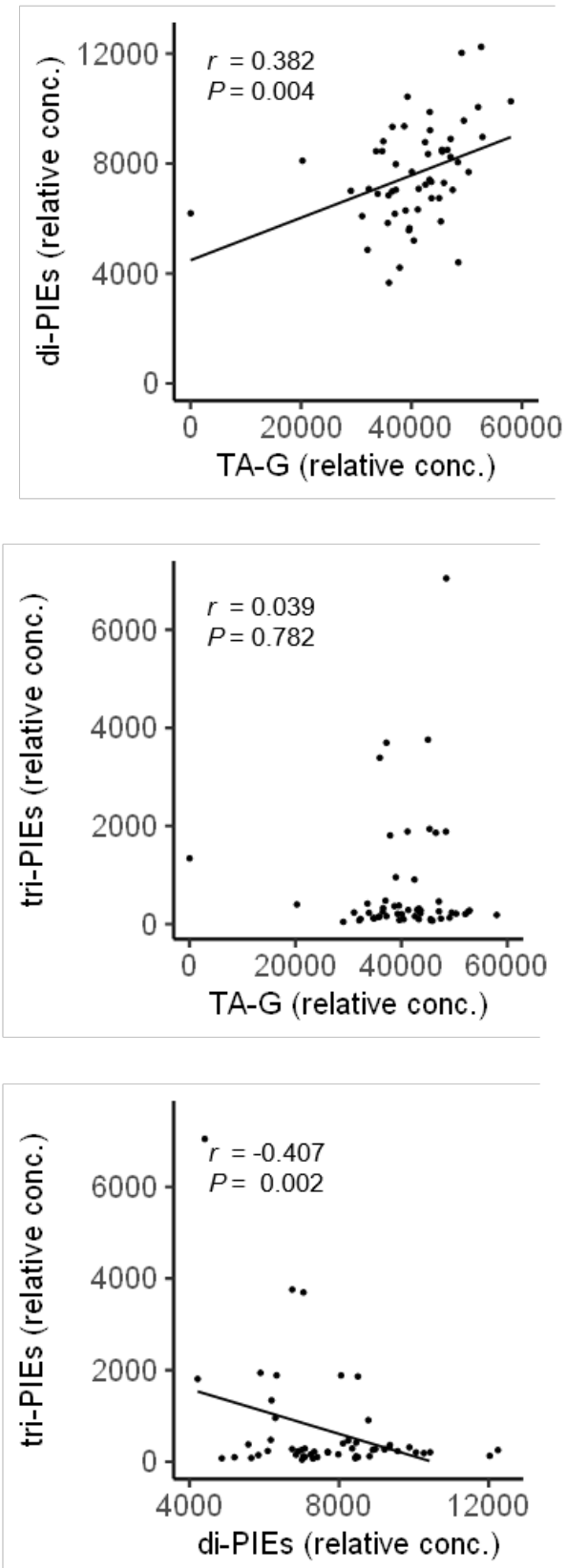

Figure 3 Covariation of the three analysed classes of latex secondary metabolites for plants growing in natural habitat (a) and plants growing in greenhouse (b). Each dot represents one of the 63 sampled $T$. officinale populations. Pearson's $r$ and corresponding $P$-values are displayed. For statistically significant correlations $(P<0.05)$, estimated linear relationships are visualized with solid lines. TA-G: taraxinic acid B-D-glucopyranosyl ester; di-PIEs: di-4hydroxyphenylacetate inositol esters; tri-PIEs: tri-4-hydroxyphenylacetate inositol esters. 
Principal components of climatic niches correlate with altitude and latitude

PRED

Annual precipitation

$-0.026$

$-0.145 \quad-0.503$

RAD

Days per year with precipitation

$-0.175$

0.546

SUN

Annual mean of global radiation

0.114

0.500

TM

Annual sunshine duration

0.435

$-0.008$

TMN

Annual mean temperature

0.342

$-0.125$

TMX

Annual mean of the minimal temperature per day

TOD

Annual mean of the maximal temperature per day

0.375

0.107

T25D

To explore the effect of abiotic and biotic factors on the latex profile of $T$. officinale, we characterized the environmental conditions of the 63 populations using climate, soil and herbivory variables and tested for their impact on latex secondary metabolites. For soil and herbivory measures we included two variables each, whereas the climatic data consisted of ten in parts strongly correlated meteorological variables (Table 1) and was subjected to dimensionality reduction by PCA, resulting in two climatic components (climPCA1, climPCA2). climPCA1 explained $52.6 \%$ of the total variation in climatic variables, and climPCA2 explained a further $23.4 \%$ of the total variation (Fig. $4 a$ ). Loading scores indicate that climPCA1 was primarily determined by variation in annual temperature (Table 1, Fig. 4a), while climPCA2 was determined by sunshine intensity and inversely correlated with precipitation (Table 1, Fig. 4a). The correlation analysis with geographical variables revealed that climPCA1 was highly correlated with altitude (Pearson's $r=-0.95, P \leq 0.001$, Fig. 4b), whereas climPCA2 was correlated with latitude (Pearson's $r=-0.53, P \leq 0.001$, Fig. 4b). Neither climPCA1 nor climPCA2 were correlated with longitude (Pearson's $r=0.01, P=0.96$ respectively Pearson's

$374 r=-0.14, P=0.28)$. No correlations were found among the climate, soil and herbivory 
376 (Table S2).

$\mathbf{a}$

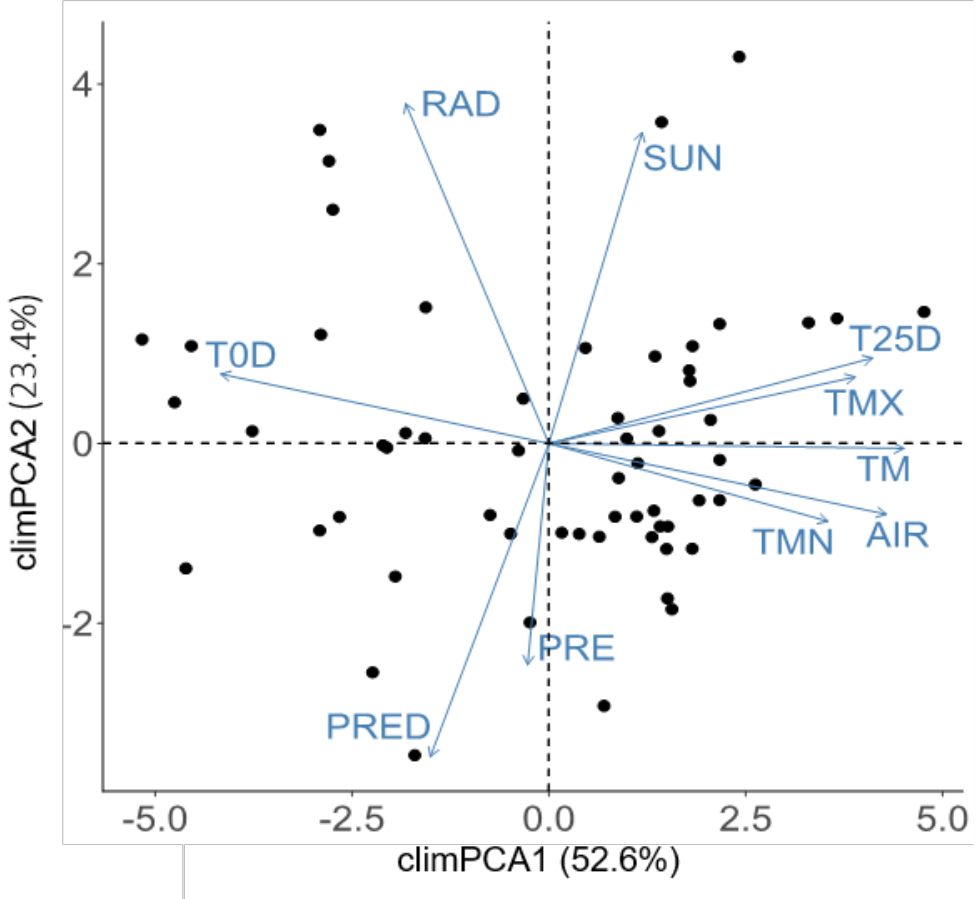

b
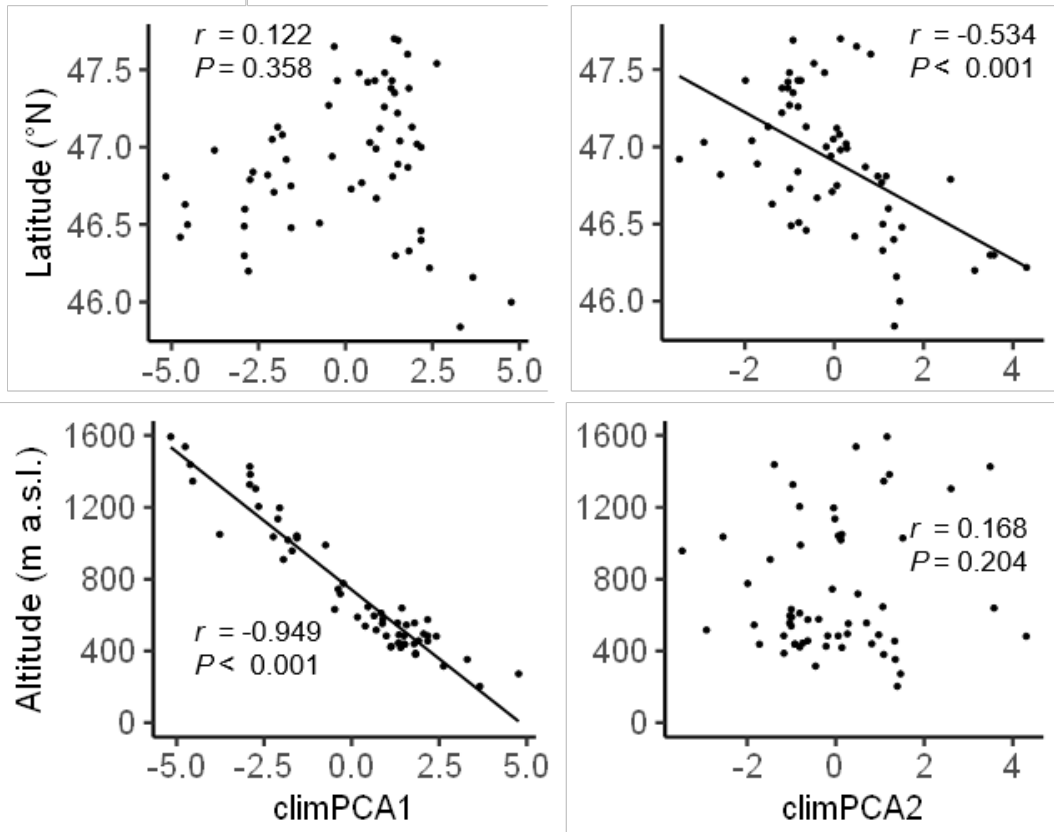

Figure 4 Climatic conditions of the sampled T. officinale populations. (a) Biplot of a principal component analysis of the climatic conditions of the populations. The first two axes (climPCA1, climPCA2) are shown, which explain $76 \%$ of cumulative variance. Each dot represents one of the 63 sampled populations. Blue vectors represent the climatic variables. AIR: annual mean of air pressure; PRED: annual precipitation; RAD: annual mean of global radiation; SUN: annual 
sunshine duration; TM: annual mean temperature; TMN: annual mean of the minimal temperature per day; TMX: annual mean of the maximal temperature per day; TOD: days per year with a minimal temperature below $0{ }^{\circ} \mathrm{C}$; T25D: Days per year with maximal temperature over $25^{\circ} \mathrm{C}$. (b) Pearson correlations of the first and second principal components (climPCA1, climPCA2) of the climatic conditions with the position parameters (altitude and latitude) of the sampled $T$. officinale populations. Each dot represents one of the 63 sampled populations. Linear correlation lines and corresponding $r$ - and $P$-values of correlations are shown.

Heritable variation of latex profile is associated with climate

Using a set of linear mixed-effects models, we tested for shaping effects of climatic,

393 soil and herbivory parameters on the concentrations of latex secondary metabolites across all populations in both plants growing in natural habitat (F0) and plants growing in the greenhouse

395 (F2). We found similar patterns for both generations of plants, which confirms a high degree of heritable variation in latex profiles (Table 2, Fig. 5). The mixed model analyses further revealed

397 distinct effects of the environmental variables depending on the class of secondary metabolite

398 (Table 2). The concentration of TA-G was negatively associated with climPCA2 alone (LMEM, $399 X^{2}=8.98, P=0.003$, Fig. 5a for F0 and $X^{2}=10.03, P=0.001$, Fig. 5b for F2, Table 2). As 400 climPCA2 was positively correlated with annual sun intensity and negatively correlated with 401 latitude (Table 1, Fig. 4b), this suggests that populations from the North of Switzerland 402 produced more TA-G than populations from the sun-intense regions in the South of Switzerland 403 (Fig. 5). Interestingly, di-PIEs were not affected by climPCA2, but negatively associated with $404 \operatorname{climPCA} 1$ (LMEM, $X^{2}=6.10, P=0.014$, Fig. 5a for F0 and $X^{2}=0.11, P=0.001$, Fig. 5b for F2, 405 Table 2). climPCA1 was positively correlated with annual temperature and negatively correlated 406 with altitude (Table 1, Fig. 4b), thus, plants from populations growing at high altitude in colder 407 areas produced more di-PIEs than plants from populations growing in warmer regions at lower 408 altitude (Fig. 5). Mixed model analysis further revealed that neither soil parameters nor 409 belowground herbivore abundance were significantly linked to TA-G or di-PIE production. The 410 number of belowground herbivores per plant was weakly negatively associated with the 411 concentration of tri-PIEs for plants from natural habitats (F0) (LMEM, $X^{2}=3.91, P=0.048$, 412 Table 2, Fig. 5a). However, a scatter plot revealed that this result was largely driven by two 413 outlier populations (Fig. 5a). 
Table 2 Summary of results from mixed-effects models that relate latex secondary metabolite concentrations to variables representing the environmental conditions of the investigated $T$. officinale populations. Models have been established separately for population means of each class of secondary metabolite as response variable and separately for each $T$. officinale generation. Environmental variables (climPCA1, climPCA2, humus, pH, M. melolontha area, belowground herbivores) were included as fixed effects and the percentage of diploid plants per population as random effect. Significances of the fixed effects were estimated by Wald chisquare tests. Chi-square values are displayed as numbers, whereas plus and minus signs refer to the effect direction of each factor. Statistically significant effects with $P<0.05{ }^{* * \star} P<0.001$; ${ }^{* \star} P<0.01 ;{ }^{*} P<0.05$ ) are displayed with bold numbers and highlighted with colour patterns. TAG: taraxinic acid ß-D-glucopyranosyl ester; di-PIEs: di-4-hydroxyphenylacetate inositol esters; tri-PIEs: tri-4-hydroxyphenylacetate inositol esters.

\begin{tabular}{|c|c|c|c|c|c|c|c|}
\hline \multirow{2}{*}{ Explanatory variable } & \multicolumn{6}{|c|}{ Chi-square } & \multirow{2}{*}{$\begin{array}{l}T \text {. officinale } \\
\text { generation }\end{array}$} \\
\hline & \multicolumn{2}{|l|}{ TA-G } & \multicolumn{2}{|l|}{ di-PIEs } & \multicolumn{2}{|l|}{ tri-PIEs } & \\
\hline \multicolumn{8}{|l|}{ Climate } \\
\hline \multirow[t]{2}{*}{ climPCA1 } & 0.220 & $(+)$ & 6.098 * & $(-)$ & $2.983^{1}$ & $(+)$ & F0 \\
\hline & 1.694 & $(-)$ & 10.112 ** & $(-)$ & $1.110^{1}$ & $(+)$ & $\mathrm{F} 2$ \\
\hline \multirow[t]{2}{*}{ climPCA2 } & 8.985 ** & $(-)$ & $0.597^{1}$ & $(-)$ & $0.353^{1}$ & $(+)$ & FO \\
\hline & 10.257 ** & $(-)$ & 0.271 & $(-)$ & $2.355^{1}$ & $(+)$ & $\mathrm{F} 2$ \\
\hline \multicolumn{8}{|l|}{ Soil } \\
\hline \multirow[t]{2}{*}{ Humus } & 0.540 & $(-)$ & $1.391^{1}$ & $(-)$ & $1.588^{1}$ & $(-)$ & Fo \\
\hline & 0.017 & $(-)$ & 0.465 & $(+)$ & $0.007^{1}$ & $(-)$ & $\mathrm{F} 2$ \\
\hline \multirow[t]{2}{*}{$\mathrm{pH}$} & 0.009 & $(-)$ & $0.960^{1}$ & $(-)$ & $0.419^{1}$ & $(-)$ & F0 \\
\hline & 0.491 & $(+)$ & 0.275 & $(+)$ & $0.083^{1}$ & $(-)$ & $\mathrm{F} 2$ \\
\hline \multicolumn{8}{|l|}{ Herbivores } \\
\hline \multirow[t]{2}{*}{ M. melolontha area } & 0.433 & $(-)$ & $0.043^{1}$ & $(+)$ & $0.173^{1}$ & $(-)$ & F0 \\
\hline & 0.070 & $(+)$ & 0.406 & $(-)$ & $0.597^{1}$ & $(-)$ & $\mathrm{F} 2$ \\
\hline \multirow[t]{2}{*}{ Belowground herbivores } & 1.494 & $(-)$ & $1.126^{1}$ & $(-)$ & $3.912 * 1$ & $(-)$ & Fo \\
\hline & 0.030 & $(+)$ & 0.237 & $(-)$ & $0.206^{1}$ & $(+)$ & $\mathrm{F} 2$ \\
\hline
\end{tabular}

\footnotetext{
${ }^{1}$ log-transformation of response variable
} 
bioRxiv preprint doi: https://doi.org/10.1101/2020.01.25.919654; this version posted January 25, 2020. The copyright holder for this preprint (which was not certified by peer review) is the author/funder, who has granted bioRxiv a license to display the preprint in perpetuity. It is made available under aCC-BY-NC-ND 4.0 International license.

a Plants growing in natural habitat (F0)
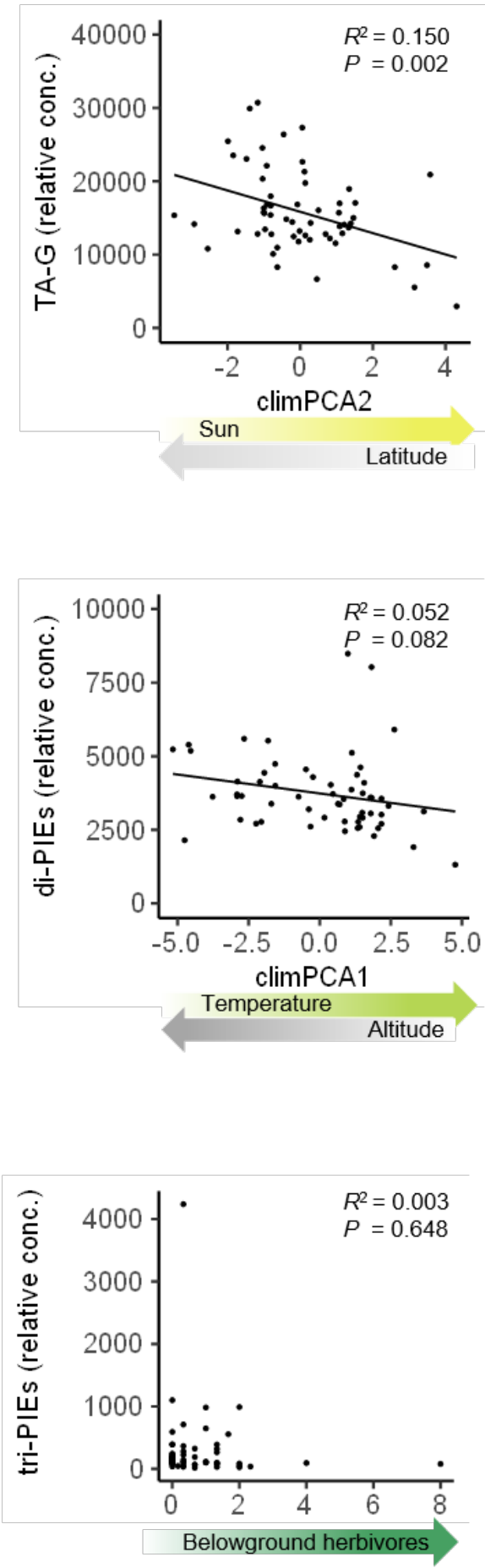

b Plants growing in greenhouse (F2)
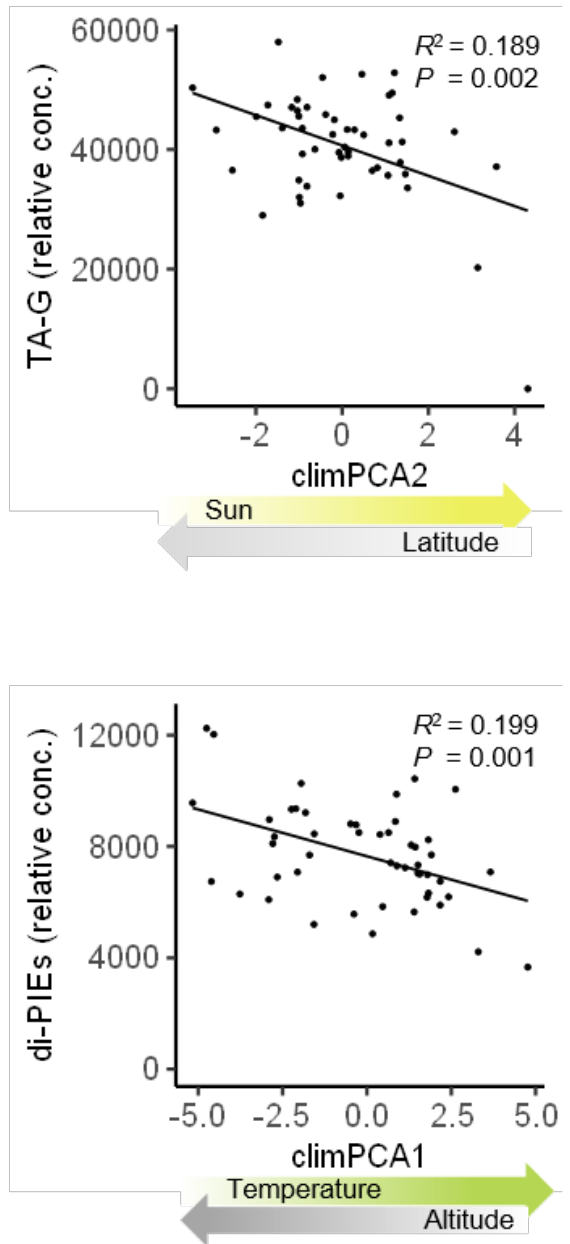
429 Figure 5 Visualization of relationships between the significant effects of the mixed-effects 430 model and the corresponding class of latex secondary metabolites for plants growing in natural habitat (a) and plants growing in greenhouse (b). Each dot represents one of the 63 sampled $T$. officinale populations. Linear regression lines and $R^{2}$ - and $P$-values of the regressions are shown. Coloured arrows illustrate intensity gradients of the corresponding environmental factors. Note that these linear regressions are different from the mixed-effects models. The regressions in this figure simplify the relationships between latex metabolites and environmental factors for illustrative purposes, while the mixed-effect models in Table 2 examine the associations in a more powerful modelling framework. TA-G: taraxinic acid B-Dglucopyranosyl ester; di-PIEs: di-4-hydroxyphenylacetate inositol esters; tri-PIEs: tri-4hydroxyphenylacetate inositol esters. 


\section{Discussion}

Plant secondary metabolites can vary considerably between populations, but the

443 contribution of the environment in shaping secondary metabolite profiles of plants by driving

444 selection or environmental plasticity is poorly understood. Our work shows that heritable

445 variation in latex secondary metabolites of $63 \mathrm{~T}$. officinale populations across Switzerland is

446 strongly linked to climatic conditions, but not to soil properties or belowground herbivore

447 abundance. Here, we discuss the implications of these findings from ecological and 448 physiological points of view.

449 The $T$. officinale populations included in this study were evenly distributed across

450 Switzerland and spanned an elevation gradient from $200-1600 \mathrm{~m}$ a.s.I. For Switzerland, the

451 occurrence of both sexual diploid and asexual triploid dandelions has been reported, with 452 diploids being found at elevations higher than $700 \mathrm{~m}$ a.s.l and triploids being found in lower 453 areas (Calame \& Felber, 2000). However, our ploidy analysis could not confirm such an 454 elevation threshold, as we found diploids and triploids at all elevations and frequently observed 455 populations with mixed cytotypes. Calame \& Felber (2000) analysed the distribution of $T$. 456 officinale cytotypes along two elevation gradients of different regions (Jura and Alps), whereas 457 in our study we did not sample directly along elevation gradients, but analysed a broader 458 spectrum of populations from all over Switzerland. The differences in the reported cytotype 459 distributions may thus be due to the different sampling ranges.

460 As a chemical interface between plants and their environment, some plant secondary 461 metabolites vary highly in concentration and composition with changing abiotic conditions 462 (Holopainen et al., 2018; Jakobsen \& Olsen, 1994; Selmar \& Kleinwächter, 2013). Fluctuating 463 patterns of sesquiterpene lactones and phenolics produced by Tithonia diversifolia, for 464 instance, correlate with seasonal changes in temperature and rainfall (Sampaio, Edrada-Ebel, 465 \& Da Costa, 2016). Our results show that the concentrations of both TA-G and di-PIEs in the 466 latex of $T$. officinale are strongly associated with the climatic conditions of the population origins, 467 and thus emphasize the central role of abiotic conditions for shaping latex composition. 468 Interestingly, despite the structural similarity of di-PIEs and tri-PIEs, we found no effect of 469 climate on tri-PIEs, which points towards distinct functions and regulations of the two groups of 470 secondary metabolites. Climatic effects on latex profiles were consistent for plants growing in 
471 natural habitat and for plants growing under greenhouse conditions two generations later,

472 although altered correlations among compounds in field- or greenhouse-grown plants suggest

473 some degree of environmental plasticity in latex secondary metabolites. Nonetheless, this

474 indicates that variation in latex profiles is at least in part heritable and suggests that climatic

475 conditions exert direct or indirect selection pressure on latex secondary metabolites in $T$.

476 officinale.

477 Variation in plant defenses between and within species are often hypothesized to follow 478 geographical gradients, which in turn are speculated to be linked to herbivore pressure (Anstett 479 et al., 2018; Moles et al., 2011; Pratt et al., 2014). Both TA-G and di-PIEs have been shown to 480 be involved in herbivore defense (Agrawal et al., 2018; Bont et al., 2017; Huber, Bont, et al., 481 2016; Huber, Epping, et al., 2016). Our results confirm a link of both metabolites with 482 geographical gradients, as the climatic variables, which influence TA-G and di-PIEs, are 483 strongly linked to altitude and latitude. We found more di-PIEs in plants from high altitudes with 484 lower temperatures, and more TA-G in plants from areas with less sun in the North of 485 Switzerland. However, as herbivore pressure varied independently of climatic variables, we 486 found no evidence for a major role of belowground herbivores in the observed genetically based 487 variation in latex secondary metabolites, contrary to our expectations. Nevertheless, we cannot 488 rule out potential hidden effects of herbivores on latex metabolites. The climatic variables used 489 in our study include 20 years of weather data at very high resolution, whereas our herbivore 490 variables either captured a single snapshot in time, or relied on rough, potentially inaccurate 491 historic estimates. Thus, the two herbivore variables may have failed to accurately represent 492 the actual herbivore abundances of the past (Huber, Bont, et al., 2016). Furthermore, herbivore 493 effects could manifest themselves through interactions with climate conditions or other 494 variables. Plant responses to abiotic and biotic stresses are controlled by the same interactive 495 hormonal network, hence combined stresses may lead to complex hormonal interactions 496 (Nguyen, Rieu, Mariani, \& van Dam, 2016). In maize, for example, root herbivory induces 497 hydraulic changes in the leaves and triggers abscisic acid (ABA) accumulation (Erb et al., 498 2011). ABA again is essentially involved in regulating responses to abiotic stresses and 499 stimulates for instance stomata closure, which is crucial for limiting desiccation (Daszkowska500 Golec \& Szarejko, 2013). Thus, by influencing the water balance of the plant, root herbivores 
501 may indirectly affect the plant's response to abiotic conditions. However, we could not test for

502 interactive effects of the environmental variables included in our study, as the full set of required

503 tests would have exceeded the appropriate number of model parameters compared to the

504 number of included populations in our analysis. Thus, to shed light on this topic, further

505 experiments are needed, which test specifically the interacting effect of climatic conditions and

506 herbivore pressure on secondary metabolites at large-scale environmental variation. However,

507 given the different and specific associations between PIEs, TA-G and climatic conditions and

508 the inverse relationship between climate parameters, expected herbivore attack rates and

509 secondary metabolite concentrations, we consider it unlikely that the climate effects observed

510 here are the indirect result of climate-mediated herbivory alone.

511 There is growing evidence that many secondary metabolites are highly multifunctional

512 and serve defensive, ecological and physiological functions at the same time, which minimizes

513 the plant's fitness costs for biosynthesis and maintenance of metabolites (Bednarek \& Osbourn,

514 2009; Neilson et al., 2013). Maize plants, for instance, use the same benzoxazinoid secondary

515 metabolites for iron uptake, protection against generalist herbivores, and defence signalling

516 (Hu et al., 2018; B. Li et al., 2018; Maag et al., 2016). For another important class of defensive

517 secondary metabolites, glucosinolates, it has been shown that the metabolite 3-

518 hydroxypropylglucosinolate has signalling capacity and inhibits root growth and development

519 by the evolutionary old TOR (Target of Rapamycin) pathway (Malinovsky et al., 2017). In

520 addition, recent work shows that aliphatic glucosinolates have an important role in drought

521 conditions by regulating stomatal aperture, thus providing evidence that glucosinolates are also

522 involved in abiotic stress tolerance (Salehin et al., 2019). Our finding that TA-G and di-PIEs are

523 strongly associated to climatic conditions suggests potential alternative functions of those latex

524 secondary metabolites, and latex itself, in addition to the previous reported roles in herbivore

525 defence (Agrawal et al., 2018; Huber, Bont, et al., 2016). Both TA-G and di-PIE concentrations

526 were correlated with each other, but each compound class was affected by distinct climate

527 variables: TA-G was mainly associated with sun and rain intensity (climPCA2), whereas di-PIEs

528 were mainly associated with temperature (climPCA1). Hence, TA-G may be involved in

529 moisture regulation or linked to physiological processes that are associated with light

530 availability, whereas di-PIEs may play a role in temperature-sensitive processes. Of course 
531 these are highly speculative arguments based on correlational data, and manipulative

532 experiments are needed to further explore the role of latex secondary metabolites in climate-

533 mediated plant physiology.

534 Studies of inter- and intraspecific plant trait variation across environmental gradients,

535 such as those related to latitude and elevation, have been receiving increasing attention

536 (Anstett et al., 2018; Hahn et al., 2018; Pellissier, Roger, Bilat, \& Rasmann, 2014; Woods et

537 al., 2012). Although such studies are beyond doubt important and useful to test classic theories

538 predicting herbivore defence (Anstett et al., 2015; Moles et al., 2011) and resource allocation

539 patterns (Helsen et al., 2017; Kooyers, Greenlee, Colicchio, Oh, \& Blackman, 2015), they also

540 have to cope with the difficulty of potentially hidden dynamics along gradients. Changes in

541 abiotic and biotic factors may be correlated and interconnected to changes in geographical

542 location, which complicates the disentangling of environmental impacts on plant traits (Hahn et

543 al., 2018; Johnson \& Rasmann, 2011). Our results emphasize the importance of considering

544 multiple environmental factors when studying biogeographical patterns of plant traits, and of

545 sampling a large set of natural genotypes across a wide range of environments. We propose

546 to include the possibility of multifunctionality of secondary metabolites into the framework of

547 studies that explore trait variation in plant defences, as patterns of defence variation may be

548 explained by alternative additional functions of plant secondary metabolites. 


\section{Acknowledgements}

550 We thank Armin Komposch, Cyrill Delfgou, Gabriel Ulrich and Zephyr Züst for their help

551 during fieldwork. We are grateful to the gardeners of the University of Bern as well as to Valentin

552 Pulver, Tala Bürki, Andrea Bonini, Robin Bautzmann, Conradin Lutz, Gabriel Zala and Yves

553 Garnier for their help with experiments. We thank Pierre Mateo for drawing chemical structures.

554 Meteorological data was provided by MeteoSwiss, the Swiss Federal Office for Meteorology

555 and Climatology. This study was supported by the Swiss National Science Foundation (Grant

556 No. 153517) and the Seventh Framework Programme for Research and Technological

557 Development of the European Union (FP7 MC-CIG 629134).

558

559 Authors' contributions: ZB, TZ, MH and ME designed the study. ZB collected the data. ZB,

560 TZ and ME analysed and interpreted the data. ZB and ME wrote the first draft of the

561 manuscript. All authors contributed to the final version of the manuscript.

562

563 Data accessibility: All data supporting this study will be stored in the Dryad Digital

564 Repository and the data DOI will be included in the manuscript. 


\section{References}

566

567

568

569

570

571

572

573

574

575

576

577

578

579

580

581

582

583

584

585

586

587

588

589

590

591

592

593

594

Abdala-Roberts, L., Moreira, X., Rasmann, S., Parra-Tabla, V., \& Mooney, K. A. (2016). Test of biotic and abiotic correlates of latitudinal variation in defences in the perennial herb Ruellia nudiflora. Journal of Ecology, 104(2), 580-590. doi: 10.1111/1365-2745.12512

Agrawal, A. (2011). Current trends in the evolutionary ecology of plant defence. Functional Ecology, 25(2), 420-432. doi: 10.1111/j.1365-2435.2010.01796.x

Agrawal, A. A., Hastings, A. P., Fines, D. M., Bogdanowicz, S., \& Huber, M. (2018). Insect herbivory and plant adaptation in an early successional community. Evolution, 1-14. doi: $10.1111 /$ evo. 13451

Agrawal, A., \& Konno, K. (2009). Latex: a model for understanding mechanisms, ecology, and evolution of plant defense against herbivory. Annual Review of Ecology, Evolution, and Systematics, 40, 311-331. doi: 10.1146/annurev.ecolsys.110308.120307

Anstett, D. N., Ahern, J. R., Glinos, J., Nawar, N., Salminen, J. P., \& Johnson, M. T. J. (2015). Can genetically based clines in plant defence explain greater herbivory at higher latitudes? Ecology Letters, 18(12), 1376-1386. doi: 10.1111/ele.12532

Anstett, D. N., Ahern, J. R., Johnson, M. T. J., \& Salminen, J. P. (2018). Testing for latitudinal gradients in defense at the macroevolutionary scale. Evolution, 2129-2143. doi: 10.1111/evo.13579

Baquero, O. S. (2017). ggsn: north symbols and scale bars for maps created with "ggplot2" or "ggmap". R package version 0.4.0. See https://CRAN.R-project.org/package=ggsn.

Barton, K. E. (2014). Prickles, latex, and tolerance in the endemic Hawaiian prickly poppy (Argemone glauca): variation between populations, across ontogeny, and in response to abiotic factors. Oecologia, 174(4), 1273-1281. doi: 10.1007/s00442-013-2836-z

Bates, D., Maechler, M., Bolker, B. M., \& Walker, S. (2015). Fitting linear mixed-effects models using \{Ime4\}. Journal Of Statistical Software, 67, 1-48. doi: 10.18637/jss.v067.i01

Bednarek, P., \& Osbourn, A. (2009). Plant-microbe interactions: chemical diversity in plant defense. Science, 324, 746-748. doi: 10.1126/science.1171661

Bont, Z., Arce, C., Huber, M., Huang, W., Mestrot, A., Sturrock, C. J., \& Erb, M. (2017). A herbivore tag-and-trace system reveals contact- and density-dependent repellence of a root toxin. Journal of Chemical Ecology, 43(3), 295-306. doi: 10.1007/s10886-017-0830- 
596 Calame, F., \& Felber, F. (2000). Distribution of diploid sexual and triploid apomictic dandelions (Taraxacum sect. Ruderalia) along two altitudinal gradients in Switzerland. Botanica Helvetica, 110(2), 109-114.

599 Castelblanque, L., Balaguer, B., Martí, C., Rodríguez, J. J., Orozco, M., \& Vera, P. (2017).

600 Multiple facets of laticifer cells. Plant Signaling and Behavior, 12(7), 1-5. doi: $10.1080 / 15592324.2017 .1300743$

602 Castillo, G., Cruz, L. L., Hernández-Cumplido, J., Oyama, K., Flores-Ortiz, C. M., Fornoni, J., 603 ... Núñez-Farfán, J. (2013). Geographic association and temporal variation of chemical 604 and physical defense and leaf damage in Datura stramonium. Ecological Research, 28(4), 663-672. doi: 10.1007/s11284-013-1059-4

Coll Aráoz, M. V., Mercado, M. I., Grau, A., \& Catalán, C. A. N. (2016). Intraspecific variation 607 of sesquiterpene lactones associated to a latitudinal gradient in Smallanthus macroscyphus (Heliantheae: Asteraceae). Chemoecology, 26(4), 143-151. doi:

610 Cunningham, S. A., Summerhayes, B., \& Westoby, M. (1999). Evolutionary divergences in leaf structure and chemistry, comparing rainfall and soil nutrient gradients. Ecology, 69(4),

613 Daszkowska-Golec, A., \& Szarejko, I. (2013). Open or close the gate - stomata action under the control of phytohormones in drought stress conditions. Frontiers in Plant Science, 4, 1-16. doi: $10.3389 /$ fpls.2013.00138

616 de Costa, F., Yendo, A. C. A., Fleck, J. D., Gosmann, G., \& Fett-Neto, A. G. (2013). 617 Accumulation of a bioactive triterpene saponin fraction of Quillaja brasiliensis leaves is associated with abiotic and biotic stresses. Plant Physiology and Biochemistry, 66, 5662. doi: 10.1016/j.plaphy.2013.02.003

620 Dubuis, A., Giovanettina, S., Pellissier, L., Pottier, J., Vittoz, P., \& Guisan, A. (2013). Improving 621 the prediction of plant species distribution and community composition by adding edaphic to topo-climatic variables. Journal of Vegetation Science, 24(4), 593-606. doi: $10.1111 / j v s .12002$

624 Erb, M., Ko, T. G., Turlings, T. C. J., Köllner, T. G., Degenhardt, J., Zwahlen, C., ... Turlings, 

resistance. New Phytologist, 189, 308-320.

627 Fox, J., \& Weisberg, S. (2011). An $\{R\}$ companion to applied regression (second edition). Thousand Oaks CA: Sage.

629 Francisco, M., Joseph, B., Caligagan, H., Li, B., Corwin, J. A., Lin, C., ... Kliebenstein, D. J.

630 (2016). Genome wide association mapping in Arabidopsis thaliana identifies novel genes involved in linking allyl glucosinolate to altered biomass and defense. Frontiers in Plant Science, 7, 1-13. doi: 10.3389/fpls.2016.01010

Gargallo-Garriga, A., Sardans, J., Pérez-Trujillo, M., Oravec, M., Urban, O., Jentsch, A., ... Peñuelas, J. (2015). Warming differentially influences the effects of drought on stoichiometry and metabolomics in shoots and roots. New Phytologist, 207(3), 591-603. doi: 10.1111/nph.13377

Garnier, S. (2018). viridis: default color maps from "matplotlib". R package version 0.5.1. See https://CRAN.R-project.org/package=viridis.

Hagel, J. M., Yeung, E. C., \& Facchini, P. J. (2008). Got milk? The secret life of laticifers. Trends in Plant Science, 13(12), 631-639. doi: 10.1016/j.tplants.2008.09.005

Hahn, P. G., Agrawal, A. A., Sussman, K. I., \& Maron, J. L. (2018). Population variation, environmental gradients, and the evolutionary ecology of plant defense against herbivory.

644 Hartmann, T. (2007). From waste products to ecochemicals: fifty years research of plant 645 secondary metabolism. Phytochemistry, 68, $\quad 2831-2846$. doi:

647 Hauss, R., \& Schütte, F. (1976). Zur Polyphagie der Engerlinge von Melolontha melolontha L. 648 an Pflanzen aus Wiese und Ödland. Anzeiger Für Schädlingskunde, 49(9), 129-132.

649 Hazarika, P., \& Rajam, M. V. (2011). Biotic and abiotic stress tolerance in transgenic tomatoes 650 by constitutive expression of S-adenosylmethionine decarboxylase gene. Physiology and 651 Molecular Biology of Plants, 17(2), 115-128. doi: 10.1007/s12298-011-0053-y

652 Helsen, K., Acharya, K. P., Brunet, J., Cousins, S. A. O., Decocq, G., Hermy, M., ... Graae, B. 653 J. (2017). Biotic and abiotic drivers of intraspecific trait variation within plant populations 654 of three herbaceous plant species along a latitudinal gradient. BMC Ecology, 17(38), 1- 
Hervé, M. (2018). Package "RVAideMemoire."

657 Holopainen, J. K., Virjamo, V., Ghimire, R. P., Blande, J. D., Julkunen-Tiitto, R., \& Kivimäenpää, M. (2018). Climate change effects on secondary compounds of forest trees in the Northern Hemisphere. Frontiers in Plant Science, 9, 1-10. doi: 10.3389/fpls.2018.01445

660 Honek, A., \& Martinkova, Z. (2005). Pre-dispersal predation of Taraxacum officinale (dandelion) seed. Journal of Ecology, 93(2), 335-344. doi: 10.1111/j.1365-2745.2005.00986.x

662 Hu, L., Mateo, P., Ye, M., Zhang, X., Berset, J. D., Handrick, V., ... Erb, M. (2018). Plant iron acquisition strategy exploited by an insect herbivore. Science, 361, 694-697. doi: 10.1126/science.aat4082

Huber, M., Bont, Z., Fricke, J., Brillatz, T., Aziz, Z., Gershenzon, J., \& Erb, M. (2016). A belowground herbivore shapes root defensive chemistry in natural plant populations.

Huber, M., Epping, J., Schulze Gronover, C., Fricke, J., Aziz, Z., Brillatz, T., ... Erb, M. (2016). Proceedings. Biological Sciences / The Royal Society, 283, 1-10. doi: A latex metabolite benefits plant fitness under root herbivore attack. PLoS Biology, 14, 127. doi: $10.1371 /$ journal.pbio. 1002332

Huber, M., Triebwasser-Freese, D., Reichelt, M., Heiling, S., Paetz, C., Chandran, J. N., ... Erb, M. (2015). Identification, quantification, spatiotemporal distribution and genetic variation of major latex secondary metabolites in the common dandelion (Taraxacum officinale agg.). Phytochemistry, 115, 89-98. doi: 10.1016/j.phytochem.2015.01.003

Jakobsen, H. B., \& Olsen, C. E. (1994). Influence of climatic factors on emission of flower volatiles in situ. Planta, 192(3), 365-371. doi: 10.1007/BF00198572

Johnson, M. T. J., \& Rasmann, S. (2011). The latitudinal herbivory defence hypothesis takes a detour on the map. New Phytologist, 191(3), 589-592. 
Kassambara, A., \& Mundt, F. (2017). factoextra: extract and visualize the results of multivariate data analyses. $\mathrm{R}$ package version 1.0.5. See https:// CRAN.Rproject.org/package=factoextra.

688 Katz, E., Nisani, S., Yadav, B. S., Woldemariam, M. G., Shai, B., Obolski, U., ... Chamovitz, D. A. (2015). The glucosinolate breakdown product indole-3-carbinol acts as an auxin antagonist in roots of Arabidopsis thaliana. Plant Journal, 82(4), 547-555. doi: $10.1111 /$ tpj. 12824

Kim, J. I., Ciesielski, P. N., Donohoe, B. S., Chapple, C., \& Li, X. (2014). Chemically induced conditional rescue of the reduced epidermal fluorescence 8 mutant of Arabidopsis reveals rapid restoration of growth and selective turnover of secondary metabolite pools. Plant Physiology, 164(2), 584-595. doi: 10.1104/pp.113.229393

Kobayashi, T., \& Nishizawa, N. K. (2012). Iron uptake, translocation, and regulation in higher plants. Annual Review of Plant Biology, 63, 131-152. doi: 10.1146/annurev-arplant-

Konno, K. (2011). Plant latex and other exudates as plant defense systems: roles of various defense chemicals and proteins contained therein. Phytochemistry, 72(13), 1510-1530. doi: 10.1016/j.phytochem.2011.02.016

Kooyers, N. J., Greenlee, A. B., Colicchio, J. M., Oh, M., \& Blackman, B. K. (2015). Replicate altitudinal clines reveal that evolutionary flexibility underlies adaptation to drought stress in annual Mimulus guttatus. New Phytologist, 206(1), 152-165. doi: 10.1111/nph.13153

Lázaro, A., \& Totland, Ø. (2010). Population dependence in the interactions with neighbors for pollination: a field experiment with Taraxacum officinale. American Journal of Botany, 97(5), 760-769. doi: 10.3732/ajb.0900263

Li, B., Förster, C., Robert, C. A. M., Züst, T., Hu, L., Machado, R. A. R., ... Erb, M. (2018).

711 Li, J., Schuman, M. C., Halitschke, R., Li, X., Guo, H., Grabe, V., ... Baldwin, I. T. (2018). The 712 decoration of specialized metabolites influences stylar development. ELife, 7, 1-24. doi: $713 \quad 10.7554 /$ eLife.38611

714 Maag, D., Köhler, A., Robert, C. A. M., Frey, M., Wolfender, J. L., Turlings, T. C. J., ... Erb, M. 
Malinovsky, F. G., Thomsen, M. L. F., Nintemann, S. J., Jagd, L. M., Bourgine, B., Burow, M., \& Kliebenstein, D. J. (2017). An evolutionarily young defense metabolite influences the root growth of plants via the ancient TOR signaling pathway. ELife, 6, 1-24. doi: 10.7554/eLife.29353

Meindl, G. a, Bain, D. J., \& Ashman, T.-L. (2013). Edaphic factors and plant-insect interactions: direct and indirect effects of serpentine soil on florivores and pollinators. Oecologia, 173(4), 1355-1366. doi: 10.1007/s00442-013-2711-y

Mithöfer, A., \& Boland, W. (2012). Plant defense against herbivores: chemical aspects. Annual Review of Plant Biology, 63, 431-450. doi: 10.1146/annurev-arplant-042110-103854

Moles, A. T., Wallis, I. R., Foley, W. J., Warton, D. I., Stegen, J. C., Bisigato, A. J., ... Prior, L. D. (2011). Putting plant resistance traits on the map: a test of the idea that plants are better defended at lower latitudes. New Phytologist, 191(3), 777-788. doi: 10.1111/j.1469-8137.2011.03732.x

Møller, B. L. (2010). Functional diversifications of cyanogenic glucosides. Current Opinion in Plant Biology, 13(3), 338-347. doi: 10.1016/j.pbi.2010.01.009

Moore, B. D., Andrew, R. L., Külheim, C., \& Foley, W. J. (2014). Explaining intraspecific diversity in plant secondary metabolites in an ecological context. The New Phytologist,

Neilson, E. H., Goodger, J. Q. D., Woodrow, I. E., \& Møller, B. L. (2013). Plant chemical defense: at what cost? Trends in Plant Science, 18(5), 250-258. doi: 10.1016/j.tplants.2013.01.001

Nguyen, D., Rieu, I., Mariani, C., \& van Dam, N. M. (2016). How plants handle multiple stresses: hormonal interactions underlying responses to abiotic stress and insect herbivory. Plant Molecular Biology, 91(6), 727-740. doi: 10.1007/s11103-016-0481-8

Pellissier, L., Roger, A., Bilat, J., \& Rasmann, S. (2014). High elevation Plantago lanceolata plants are less resistant to herbivory than their low elevation conspecifics: is it just temperature? Ecography, 37(10), 950-959. doi: 10.1111/ecog.00833

Peters, N. K., Frost, J. W., \& Long, S. R. (1986). A plant flavone, luteolin, induces expression 
of Rhizobium meliloti nodulation genes. Science, 233(4767), 977-980.

746 Pratt, J. D., Keefover-Ring, K., Liu, L. Y., \& Mooney, K. A. (2014). Genetically based latitudinal variation in Artemisia californica secondary chemistry. Oikos, 123(8), 953-963. doi: 10.1111/oik.01156

Qi, L., Yang, J., Yuan, Y., Huang, L., \& Chen, P. (2015). Overexpression of two R2R3-MYB genes from Scutellaria baicalensis induces phenylpropanoid accumulation and enhances oxidative stress resistance in transgenic tobacco. Plant Physiology and Biochemistry, 94, 235-243. doi: 10.1016/j.plaphy.2015.06.007

R Core Team. (2017). R: a language and environment for statistical computing. doi: $10.1007 / 978-3-540-74686-7$

Raj, S., Das, G., Pothen, J., \& Dey, S. K. (2005). Relationship between latex yield of Hevea brasiliensis and antecedent environmental parameters. International Journal of Biometeorology, 49(3), 189-196. doi: 10.1007/s00484-004-0222-6

758 Rasmann, S., \& Agrawal, A. a. (2008). In defense of roots: a research agenda for studying plant resistance to belowground herbivory. Plant Physiology, 146(3), 875-880. doi: 10.1104/pp.107.112045

Salehin, M., Li, B., Tang, M., Katz, E., Song, L., Ecker, J. R., ... Estelle, M. (2019). Auxinsensitive Aux/IAA proteins mediate drought tolerance in Arabidopsis by regulating glucosinolate levels. Nature Communications, 10(1). doi: 10.1038/s41467-019-12002-1

764 Sampaio, B. L., Edrada-Ebel, R., \& Da Costa, F. B. (2016). Effect of the environment on the secondary metabolic profile of Tithonia diversifolia: a model for environmental metabolomics of plants. Scientific Reports, 6, 1-11. doi: 10.1038/srep29265

767 Schäfer, P., Pfiffi, S., Voll, L. M., Zajic, D., Chandler, P. M., Waller, F., ... Kogel, K. H. (2009). Manipulation of plant innate immunity and gibberellin as factor of compatibility in the mutualistic association of barley roots with Piriformospora indica. Plant Journal, 59(3),

771 Schuman, M. C., \& Baldwin, I. T. (2016). The layers of plant responses to insect herbivores. Annual Review of Entomology, 61, 373-394. doi: 10.1146/annurev-ento-010715-023851

773 Selmar, D., \& Kleinwächter, M. (2013). Influencing the product quality by deliberately applying 774 drought stress during the cultivation of medicinal plants. Industrial Crops and Products, 
Stevens, M. T., Brown, S. C., Bothwell, H. M., \& Bryant, J. P. (2016). Biogeography of Alaska paper birch (Betula neoalaskana): latitudinal patterns in chemical defense and plant architecture. Ecology, 97(2), 494-502. doi: 10.1890/15-0968

Stevenson, P. C., Nicolson, S. W., \& Wright, G. A. (2017). Plant secondary metabolites in nectar: impacts on pollinators and ecological functions. Functional Ecology, 31, 65-75. doi: $10.1111 / 1365-2435.12761$

Stewart-Wade, S. M., Neumann, S., Collins, L. L., \& Boland, G. J. (2002). The biology of Canadian weeds. 117. Taraxacum officinale G. H. Weber ex Wiggers. Canadian Journal of Plant Science, 825-853.

Tackenberg, O., Poschlod, P., \& Kahmen, S. (2003). Dandelion seed dispersal: the horizontal wind speed does not matter for long-distance dispersal - it is updraft! Plant Biology, 5, 451-454. doi: 10.1055/s-2003-44789

Takakura, K. I., Matsumoto, T., Nishida, T., \& Nishida, S. (2011). Effective range of reproductive interference exerted by an alien dandelion, Taraxacum officinale, on a native congener. Journal of Plant Research, 124(2), 269-276. doi: 10.1007/s10265-010-0368-8

van Dam, N. M. (2009). Belowground herbivory and plant defenses. Annual Review of Ecology,

doi:

10.1146/annurev.ecolsys.110308.120314

Verduijn, M. H., Van Dijk, P. J., \& Van Damme, J. M. M. (2004). The role of tetraploids in the sexual-asexual cycle in dandelions (Taraxacum). Heredity, 93(4), 390-398. doi:

Wallis, C. M., Huber, D. P. W., \& Lewis, K. J. (2011). Ecosystem, location, and climate effects on foliar secondary metabolites of lodgepole pine populations from Central British Columbia. Journal of Chemical Ecology, 37(6), 607-621. doi: 10.1007/s10886-011-9958-

801 Wickham, H. (2016). ggplot2: elegant graphics for data analysis. Springer-Verlag New York.

802 Woods, E. C., Hastings, A. P., Turley, N. E., Heard, S. B., Agrawal, A., Monographs, S. E., ... 803 Agrawal, A. A. (2012). Adaptive geographical clines in the growth and defense of a native plant. Ecological Monographs, 82(2), 149-168. 
805 Zhou, M., Callaham, J. B., Reyes, M., Stasiak, M., Riva, A., Zupanska, A. K., ... Ferl, R. J.

806 (2017). Dissecting low atmospheric pressure stress: transcriptome responses to the

807 components of hypobaria in Arabidopsis. Frontiers in Plant Science, 8, 1-13. doi:

$808 \quad 10.3389 /$ fpls.2017.00528

809 Zidorn, C. (2010). Altitudinal variation of secondary metabolites in flowering heads of the

810 Asteraceae: trends and causes. Phytochemistry Reviews, 9(2), 197-203. doi:

$811 \quad 10.1007 / s 11101-009-9143-7$

812 Züst, T., Heichinger, C., Grossniklaus, U., Harrington, R., Kliebenstein, D. J., \& Turnbull, L. A. 813 (2012). Natural enemies drive geographic variation in plant defenses. Science, 338, 116-

814 120.

815 